DOI: http://dx.doi.org/10.21123/bsj.2016.13.2.0388

\title{
The Act Of An Operator
}

\section{Samira Naji Kadhim}

Zainab Abed Atiya

Department of Mathematics, College of Science for Women, University of Baghdad.

E-mail:picanto.korea@gmail.com

Received 22/3/ 2015

Accepted 19/8/ 2015

(c) 1 EY NC ND This work is licensed under a Creative Commons Attribution-NonCommercialNoDerivatives 4.0 International Licens

\begin{abstract}
:
In this paper we will study some of the properties of an operator by looking at the associated S-act of this operator, and conversely. We look at some operators, like one to one operators, onto operators. On the other hand, we look at some act theoretic concepts, like faithful acts, finitely generated acts, singular acts, separated acts, torsion free acts and noetherian acts. We try to determine what properties of $\mathrm{T}$ make the associated S-act has any of these properties.
\end{abstract}

Key words: faithful act, finitely generated act, singular act, separated act, torsion free act, noetherian act.

\section{Introduction:}

The S-acts have been introduced and studied, for example, in $[1,2]$. In this paper we study $\mathrm{S}$-act of linear operator. Let $\mathrm{V}$ be a normed space over a field $\mathrm{F}$, $\mathrm{T}$ be a bounded operator on $\mathrm{V}$, and let $S=\left\{e^{x}: x \in R\right\} \quad$ be the semigroup. Define

$\mu: S \times V \rightarrow V \quad$ by $\mu\left(e^{x}, v\right)=e^{T}(v)$, this function makes $\mathrm{V}$ a left $\mathrm{S}$-act, denote by $V_{T}$ and we call it the associated $\mathrm{S}$-act of $\mathrm{T}$. we will explain this definition by some examples, and give some basic facts about the associated $V_{T}$ We introduce the form of every element in $V_{T}$, see proposition (2). and study if two operator $\mathrm{T}$ and $\mathrm{S}$ are similar then $V_{T}$ is isomorphic to $V_{S}$, see proposition (6). We show that for any operator $\mathrm{T}$ then the $\mathrm{S}$-act $V_{T}$ is faithful act, separated act, and torsion free act. We prove if $T$ is onto and $V_{T}$ is finitely generated, then $\mathrm{V}$ is finite dimensional, see proposition (9). We prove for any operator $T$ and $V_{T}$ is singular $S$-act then $\mathrm{V}$ is generated by one element, see proposition (12). We show if $\mathrm{V}$ is a finite dimensional normed space and $\mathrm{T}$ is similar to any operator $\mathrm{J}$ from $\mathrm{R}$ to $\mathrm{R}$ then $V_{T}$ is Noetherian S-act if and only if $\mathrm{S}$ is Noetherian.

\section{Main results:}

In this section we introduce the construction of associated S-act to each bounded operator $\mathrm{T}$ on a normed space $\mathrm{V}$. We illustrate the construction by some examples and we prove some basic facts about the act $\mathrm{V}_{\mathrm{T}}$. We start by the following:

Definition 1. Let $\mathrm{V}$ be a normed space over a field $\mathrm{F}$, let $\mathrm{T}$ be a bounded linear operator acting on the elements of $\mathrm{V}$ on the left. 
Let $S$ be a semigroup such that $S=\left\{e^{x}: x\right.$ $\in \mathrm{R}\}$

Define $\mu: \mathrm{S} \times \mathrm{V} \rightarrow \mathrm{V}$ by $\mu\left(\mathrm{e}^{\mathrm{x}}, \mathrm{v}\right)=$ $\mathrm{e}^{\mathrm{T}}(\mathrm{v}), \mathrm{v} \in \mathrm{V}$.

Note $e^{T}$ is defined since $T$ is bounded. [3]

We note that $\mu$ is well defined since every vector is act over a field ([1] ,p.46).

It is easy to check that $\mu$ makes $V$ a left $\mathrm{S}$-act. We shall denote this act by $\mathrm{V}_{\mathrm{T}}$, and we call it the associated $\mathrm{S}$-act of $\mathrm{T}$.

In this proposition we introduce the form of each element of $\mathrm{V}_{\mathrm{T}}$ :

Proposition 2. If $K=\left\{V_{j}, j \in \Lambda\right\}$ is a basis for $\mathrm{V}$, then each element of $\mathrm{V}_{\mathrm{T}}$ can be written in the form

$\lim _{n \rightarrow \infty} \sum_{i=0}^{n} \frac{T^{i}}{i !} \quad \sum_{j \in \Lambda} a_{j} v_{j}=\lim _{n \rightarrow \infty}$

$\mathrm{p}_{\mathrm{n}}(\mathrm{T}) . \mathrm{V}$

The symbol $\sum_{j \in \wedge}$ means the sum is taken over a finite subset of $\Lambda$.

Proof: We define $\mu: \mathrm{S} \times \mathrm{V} \longrightarrow \mathrm{V}$ by $\mu\left(\mathrm{e}^{\mathrm{x}} \cdot \mathrm{v}\right)=\mathrm{e}^{\mathrm{T}}(\mathrm{V})$

Then $\mu\left(e^{x} . \mathrm{v}\right)=e^{T}(\mathrm{v})=\sum_{i=0}^{\infty} \frac{T^{i}}{i !}(\mathrm{v})$,

Let $\mathrm{w} \in \mathrm{V}_{\mathrm{T}}$ then $\mathrm{w}=\sum_{i=0}^{\infty} \frac{T^{i}}{i !}(\mathrm{v})$.

Thus $w=\left(I+T+\frac{T^{2}}{2 !}+\frac{T^{3}}{3 !}+\cdots\right)(\mathrm{v})$, since $K=\left\{V_{j}, j \in \wedge\right\}$ is abasis for $V$ this give $\mathrm{W}=\left(I+T+\frac{T^{2}}{2 !}+\frac{T^{3}}{3 !}+\right.$ $\cdots)\left(\sum_{j \in \wedge} a_{j} v_{j}\right) \quad=I\left(\sum_{j \in \wedge} a_{j} v_{j}\right)+$ $T\left(\sum_{j \in \wedge} a_{j} v_{j}\right)+\frac{T^{2}}{2 !}\left(\sum_{j \in \wedge} a_{j} v_{j}\right)+\cdots$

$=\sum_{i=0}^{\infty} \frac{T^{i}}{i !}\left(\sum_{j \in \wedge} a_{j} v_{j}\right)$

But the series $\sum_{i=0}^{\infty} \frac{T^{i}}{i !}$ converges in $\mathrm{B}$ $(\mathrm{H})$, then

$w=\lim _{n \rightarrow \infty} \sum_{i=0}^{n} \frac{T^{i}}{i !}\left(\sum_{j \in \wedge} a_{j} v_{j}\right)$

$=\lim _{n \rightarrow \infty} p_{n}(T) . V \quad$ Вy [4]

Examples 3.

1. Let $\left\{v_{j}: j \in \wedge\right\}$ be a basis for a normed space $\mathrm{V}$. Let $O$ be the zero operator, recall $O^{o}=I$. If $w \in V_{o}$ then by proposition (2) we get
$w=e^{T}(v)=e^{o}(v)$ then $w=$ $I\left(\sum_{j \in \wedge} a_{j} v_{j}\right)$, then $w=\sum_{j \in \wedge} a_{j}$, since $e^{o}=I([3], \mathrm{p} .26)$

2. Let $I: V \rightarrow V$ be the identity operator on $\mathrm{V},\left\{v_{j}: j \in \wedge\right\}$ be a basis for a normed space $\mathrm{V}$ and let $w \in V_{I}$ then by proposition (2) we get

$w=e^{T}(v)=e^{I}(v)=$

I.e $\left(\sum_{j \in \wedge} a_{j} v_{j}\right)=$

I. $\sum_{n=0}^{\infty} \frac{1}{n !}\left(\sum_{j \in \wedge} a_{j} v_{j}\right)=$

$\sum_{n=0}^{\infty} \frac{1}{n !}\left(\sum_{j \in \wedge} a_{j} v_{j}\right)$, since $e^{I}=\mathrm{I}$. e ([3], p.26)

$=\lim _{n \rightarrow \infty} \sum_{i=0}^{n} \frac{1}{i !}\left(\sum_{j \in \wedge} a_{j} v_{j}\right)$, put $a_{n}=$ $\sum_{i=0}^{n} \frac{1}{i !}$, then

$w=\lim _{n \rightarrow \infty} a_{n}\left(\sum_{j \in \wedge} a_{j} v_{j}\right)$

3. Let $\left\{v_{j}: j \in \wedge\right\}$ be a basis for a normed space $\mathrm{V}$, and $\mathrm{T}$ be a a nilpotent operator on $\mathrm{V}$ (i.e. $T^{n}=$ 0 and $T^{n-1} \neq 0$ for some positive integer $\mathrm{n}$ )

Let $w \in V_{T}$ then by proposition (2), we have

$$
\begin{aligned}
& w=e^{T}(v)=\left(1+T+\frac{T^{2}}{2 !}+\cdots+\frac{T^{n}}{n !}+\right. \\
& \quad \cdots) v=\left(1+T+\frac{T^{2}}{2 !}+\cdots+\right. \\
& \left.\quad \frac{T^{n-1}}{(n-1) !}\right)\left(\sum_{j \in \wedge} a_{j} v_{j}\right) \\
& =p_{n-1}(T)\left(\sum_{j \in \wedge} a_{j} v_{j}\right)=p_{n-1}(T) \cdot v
\end{aligned}
$$

Lemma 4. Let $\mathrm{T}$ be a nilpotent operator on $\mathrm{V}$, then $V_{T}$ is $\mathrm{S}$ - act if and only if $V_{T}$ is $\mathrm{R}$-module, where $\mathrm{R}$ be the ring of polynomials in one variable with coefficients in F.

Proof: Suppose $V_{T}$ is S- act we want to prove $\mathrm{V}_{\mathrm{T}}$ is $\mathrm{R}$-module.

Let $w \in \mathrm{V}_{\mathrm{T}}, \quad$ then $w=p_{n-1}(T) . v$, then $V_{T}$ is R-module. [5]

Conversely, assume $V_{T}$ is R-module then $V_{T}$ is S-act. ([2], p.13)

Remark 5. If $M$ is a right R-module, then $M$ is $(R,$.$) -act. ([2], p.13)$

Note the converse is not true, to explain this we give example,

let $S=\left\{\mathrm{e}^{\mathrm{x}}: \mathrm{x} \in \mathrm{R}\right\}$ then $\mathrm{S}$ is left $\mathrm{S}$-act which denoted $S_{S}$,to prove this 
define $\mu: S \times S \rightarrow S$ by

$\mu\left(\mathrm{e}^{\mathrm{x} 1}, \mathrm{e}^{\mathrm{x} 2}\right)=\mathrm{e}^{\mathrm{x} 1+\mathrm{x} 2} \quad \forall \mathrm{x}_{1}, \mathrm{x}_{2} \in$

$\mathrm{R}, \forall \mathrm{x}_{1} \cdot \mathrm{x}_{2}=\mathrm{x}_{2} \cdot \mathrm{x}_{1}$

Then $\mathrm{s}_{1} \cdot\left(\mathrm{s}_{2} \mathrm{~s}_{3}\right)=\mathrm{e}^{\mathrm{x} 1}\left(\mathrm{e}^{\mathrm{x} 2} \mathrm{e}^{\mathrm{x} 3}\right)=$

$\mathrm{e}^{\mathrm{x} 1}\left(\mathrm{e}^{\mathrm{x} 2+\mathrm{x} 3}\right)=\mathrm{e}^{\mathrm{x} 1+\mathrm{x} 2+\mathrm{x} 3}=$

$\left(\mathrm{e}^{\mathrm{x} 1+\mathrm{x} 2}\right) \cdot \mathrm{e}^{\mathrm{x} 3}=\left(\mathrm{s}_{1} \mathrm{~s}_{2}\right) \cdot \mathrm{s}_{3}$, then

$\mathrm{S}$ is act over $\mathrm{S}$. But $S_{S}$ is not module with $(+,$.$) , since (S,+,$.$) is not Ring$ because it doesn't satisfy a binary

operation with (+), this give $S_{S}$ is act but not module.

Proposition 6. Let $\mathrm{T}$ and $\mathrm{S}$ be two operators on $\mathrm{V}$. If $\mathrm{S}$ is similar to $\mathrm{T}$ then $V_{S}$ is isomorphic to $V_{T}$.

Proof: Assume that $\mathrm{T}$ and $\mathrm{S}$ are similar, and then there exist an invertible operator $\mathrm{h}$ on $\mathrm{V}$. Such that $\mathrm{h} \mathrm{T} \mathrm{h}^{-1}=$ $\mathrm{S}$ ([6],p.156), then $\left(\mathrm{h} \mathrm{S} \mathrm{h}^{-1}=\right.$

$\mathrm{T}) . \mathrm{h}$ this give $\mathrm{hS}=\mathrm{Th}$

since $\mathrm{h} S=\mathrm{T} h$, then

$\mathrm{h} \mathrm{S}^{\mathrm{n}}=\mathrm{hSS}^{n-1}=\mathrm{T} \mathrm{hS}^{n-1}=\mathrm{ThSS}^{\mathrm{n}-2}=\mathrm{TTh}$ $\mathrm{S}^{\mathrm{n}-2}=\mathrm{T}^{2} \mathrm{hS}^{\mathrm{n}-2}=\mathrm{T}^{2} \mathrm{hSS}^{\mathrm{n}-3}=\mathrm{T}^{2} \mathrm{ThS}^{\mathrm{n}-3}=$ $\mathrm{T}^{3} \mathrm{hS}^{\mathrm{n}-3}=\mathrm{T}^{3} \mathrm{hSS}^{\mathrm{n}-4}=\mathrm{T}^{3} \mathrm{ThS}^{\mathrm{n}-4}=$ $\mathrm{T}^{4} \mathrm{hS}^{\mathrm{n}-4}=\cdots=\mathrm{T}^{\mathrm{n}} \mathrm{h}$, Then $\mathrm{h} \mathrm{e}^{\mathrm{s}}=$ $\mathrm{e}^{\mathrm{T}} \mathrm{h}$

Define $\mathrm{h}^{\prime}: \mathrm{V}_{\mathrm{s}} \rightarrow \mathrm{V}_{\mathrm{T}}$ by $\left(e^{s}(v)\right) h^{\prime}=e^{T}(h(v))$

To prove $h^{\prime}$ is isomorphism we must prove:

$\mathrm{h}^{\prime}$ is well defined, let $\mathrm{e}^{\mathrm{s}}\left(\mathrm{v}_{1}\right)=\mathrm{e}^{\mathrm{s}}\left(\mathrm{v}_{2}\right)$ then $h\left(e^{s}\left(v_{1}\right)\right)=h\left(e^{s}\left(v_{2}\right)\right)$ ( since $h$ is well defined). Then by equation (1), we get

$$
\mathrm{e}^{\mathrm{T}}\left(\mathrm{h}\left(\mathrm{v}_{1}\right)\right)=\mathrm{h}\left(\mathrm{e}^{\mathrm{s}}\left(\mathrm{v}_{1}\right)\right)=
$$

$h\left(e^{s}\left(v_{2}\right)\right)=e^{T}\left(h\left(v_{2}\right)\right)$, therefore

$$
\mathrm{e}^{\mathrm{T}}\left(\mathrm{h}\left(\mathrm{v}_{1}\right)\right)=\mathrm{e}^{\mathrm{T}}\left(\mathrm{h}\left(\mathrm{v}_{2}\right)\right)
$$

then by equations 2,3 we get

$\left(\mathrm{e}^{\mathrm{s}}\left(\mathrm{v}_{1}\right)\right) \mathrm{h}^{\prime}=\left(\mathrm{e}^{\mathrm{s}}\left(\mathrm{v}_{2}\right)\right) \mathrm{h}^{\prime}$, then $\mathrm{h}^{\prime}$ is well defined

To prove $h^{\prime}$ is one to one, let $\left(\mathrm{e}^{\mathrm{s}}\left(\mathrm{v}_{1}\right)\right) \mathrm{h}^{\prime}=\left(\mathrm{e}^{\mathrm{s}}\left(\mathrm{v}_{2}\right)\right) \mathrm{h}^{\prime}$, then by equation (2) we get $\mathrm{e}^{\mathrm{T}}\left(\mathrm{h}\left(\mathrm{v}_{1}\right)\right)=$ $\mathrm{e}^{\mathrm{T}}\left(\mathrm{h}\left(\mathrm{v}_{2}\right)\right)$, then by equation (1) we get $\mathrm{h}\left(\mathrm{e}^{\mathrm{s}}\left(\mathrm{v}_{1}\right)\right)=\mathrm{h}\left(\mathrm{e}^{\mathrm{s}}\left(\mathrm{v}_{2}\right)\right)$ but $\mathrm{h}$ is an invertable then $\mathrm{h}^{-1} \mathrm{~h}\left(\mathrm{e}^{\mathrm{s}}\left(\mathrm{v}_{1}\right)\right)=$ $\mathrm{h}^{-1} \mathrm{~h}\left(\mathrm{e}^{\mathrm{s}}\left(\mathrm{v}_{2}\right)\right)$, this gives $\left(\mathrm{e}^{\mathrm{s}}\left(\mathrm{v}_{1}\right)\right)=$ $\left(e^{s}\left(v_{2}\right)\right)$ therefore $h^{\prime}$ is one to one.
To prove $h^{\prime}$ is onto, let $\mathrm{e}^{\mathrm{T}}(\mathrm{v}) \in \mathrm{V}_{\mathrm{T}}$ then $\mathrm{h}^{-1}(\mathrm{v}) \in \mathrm{V}$, for $\mathrm{v} \in V$ and $\mathrm{e}^{\mathrm{s}}\left(\mathrm{h}^{-1}(\mathrm{v})\right) \in \mathrm{V}_{\mathrm{s}}$, then by equation (2) we get $\left(e^{s}\left(h^{-1}(v)\right) h^{\prime}=e^{T}\left(h\left(h^{-1}(v)\right)\right.\right.$ $=\mathrm{e}^{\mathrm{T}}(\mathrm{v})$ then $\mathrm{h}^{\prime}$ is onto.

We illustrate in the following proposition the relation between the faithful S-act and the linear operator $\mathrm{T}$. Now we need to give the definition of a faithful S-act.

Recall that $A_{s}$ a faithful left $\mathrm{S}$-act if for all $\mathrm{s}, \quad \mathrm{t} \in \mathrm{S}$ the equility $\mathrm{sa}=$ ta for all $\mathrm{a} \in \mathrm{A}_{\mathrm{s}}$, implies $\mathrm{s}=\mathrm{t}$. ([1], p.46)

Proposition 7. For any bounded operator $\mathrm{T}$ then $V_{T}$ is a faithful S-act.

Proof: we want to show that $V_{T}$ is a faithful S-act. Let $\mathrm{e}^{\mathrm{x} 1} \cdot \mathrm{e}^{\mathrm{T}}(\mathrm{v})=$ $\mathrm{e}^{\mathrm{x} 2} \cdot \mathrm{e}^{\mathrm{T}}(\mathrm{v})$

Since $\mathrm{e}^{\mathrm{T}}$ is linear transformation, this gives $\mathrm{e}^{\mathrm{x} 1} \cdot \mathrm{e}^{\mathrm{T}}(\mathrm{v})=\mathrm{e}^{\mathrm{x} 2} \cdot \mathrm{e}^{\mathrm{T}}(\mathrm{v})$, thus $\mathrm{e}^{\mathrm{T}}\left(\mathrm{e}^{\mathrm{x} 1} \cdot \mathrm{v}\right)=\mathrm{e}^{\mathrm{T}}\left(\mathrm{e}^{\mathrm{x} 2} \cdot \mathrm{v}\right)$. Since $\mathrm{e}^{\mathrm{T}}$ is one to one, then $\mathrm{e}^{\mathrm{x} 1} \cdot \mathrm{v}=\mathrm{e}^{\mathrm{x} 2} \cdot \mathrm{v}$, therefore $\left(\mathrm{e}^{\mathrm{x} 1}-\mathrm{e}^{\mathrm{x} 2}\right) \mathrm{v}=0$, this give $\mathrm{e}^{\mathrm{x} 1}=$ $\mathrm{e}^{\mathrm{x} 2}$, then $\mathrm{V}_{\mathrm{T}}$ is a faithful $\mathrm{S}$-act.

In ([1], p.63), a subset $U \neq \varnothing$ of a right $S$-act $A_{S}$ is said to be a set of generating elements or a generating set of $A_{s}$ if every element $a \in A_{s}$ can be presented as $\mathrm{a}=\mathrm{u} . \mathrm{s}$ for some $\mathrm{u} \in \mathrm{U}, \mathrm{s} \in \mathrm{S}$.In other words, $\mathrm{U}$ is a set of generating elements for $\mathrm{A}_{\mathrm{s}}$ if $\langle U\rangle$ $=U u S=\mathrm{A}_{\mathrm{s}}, \mathrm{u} \in \mathrm{U}$ where $\mathrm{uS}=$ $\{u s / s \in S\}$. we say that a right $S$-act $A_{s}$ is finitely generated if $\mathrm{A}_{\mathrm{s}}=\langle U\rangle$ for some $U,|\mathrm{U}|<\infty$.

Remark 8. If $\mathrm{V}$ is a finite dimensional normed space, then $V_{T}$ is finitely generated S-act.

The following proposition gives when the converse of remark (8) is true

Proposition 9. If $\mathrm{T}$ is onto and $V_{T}$ is finitely generated, then $V$ is finite dimensional.

Proof: we use the contradiction. Assume $\mathrm{V}$ is not finite dimensional. Let $k=$ $k(T)=\{w \in V: T w=0\}$. It is clear that $\mathrm{K}$ is as invariant subspace of $\mathrm{V}$ (since $K \subseteq \bigvee$ and $\forall w \in K, T(w)=$ 
0 but $0 \in$ subspace $K$ then $T(K) \subseteq$ $K)$ and by the first isomorphism theorem of S-act hen $T V \simeq \frac{V}{K}$. ([1],P.53), since $\mathrm{T}$ is onto then $\mathrm{TV}=\mathrm{V}$, therefore $\mathrm{V} \simeq \frac{V}{K}$. By assuming that $\mathrm{V}$ is not finite dimensional then either $\mathrm{K}$ infinite dimensional or $\mathrm{K}$ finite dimensional. $\mathrm{K}$ is an invariant subspace of $\mathrm{V}$ then we can consider $K_{T}$.

If $\mathrm{K}$ is finite dimensional then $K_{T}$ is finite generated by remark (10), the subact $K_{T}$ is generated by the set $\left\{\mathrm{e}^{\mathrm{T}}\left(\mathrm{w}_{\mathrm{j}}\right): \mathrm{j} \in \mathcal{\Lambda}\right\}$ where $\left\{\mathrm{w}_{\mathrm{j}}: \mathrm{j} \in \mathcal{\Lambda}\right\}$ is a basis for $\mathrm{K}$. But $w_{j} \in K$ given that $T w j=0$, since the restriction of $\mathrm{T}$ on $\mathrm{K}$ is the zero operator $\mathcal{O}$. Thus $K_{T}=K_{\mathcal{O}}$, therefore $K_{T}$ can not be finitely generated (see example 1 from (3),this contradicition with suppose $\mathrm{K}$ is finite dimensional.

Then we must $\mathrm{K}$ is infinite dimensional, the subact $K_{T}$ is generated by the set $\left\{\mathrm{e}^{\mathrm{T}}\left(\mathrm{w}_{\mathrm{j}}\right): \mathrm{j} \in \mathcal{\Lambda}\right\}$ where $\left\{\mathrm{w}_{\mathrm{j}}: \mathrm{j} \in \mathcal{\Lambda}\right\}$ is a basis for $\mathrm{K}$. But $w_{j} \in K$ given that $T w j=0$, since the restriction of $\mathrm{T}$ on $\mathrm{K}$ is the zero operator $\mathcal{O}$. Thus $K_{T}=K_{\mathcal{O}}$, therefore $K_{T}$ can not be finitely generated (see example 1 from (3),but $K_{T}$ is a subact of $V_{T}$ and $V_{T}$ is finitely generated. This mean infinitely generated contain in finitely generated. This contradiction shows that $\mathrm{V}$ is finite dimensional.

[7] show that an S-act A separated if for each $\mathrm{a} \neq \mathrm{b}$ in $\mathrm{A}$ there exists $\mathrm{s} \neq \mathrm{e}$ such that $\mathrm{sa} \neq \mathrm{sb}$.

Proposition 10. For any bounded operator T then $V_{T}$ is separated S-act.

Proof: Let $a \neq b$ in $V_{T}$ to prove that $V_{T}$ is separated we have to show that there exist $\mathrm{s}$ in $\mathrm{S}, \mathrm{s} \neq e$ such that $\mathrm{s} a \neq s b$.

Assume $\mathrm{sa}=\mathrm{sb}, \quad \mathrm{e} \neq \mathrm{s} \in S, \mathrm{a}, \mathrm{b} \in V_{T}$, this give $\mathrm{e}^{\mathrm{x}} \cdot \mathrm{e}^{\mathrm{T}}\left(\mathrm{v}_{1}\right)=\mathrm{e}^{\mathrm{x}} \cdot \mathrm{e}^{\mathrm{T}}\left(\mathrm{v}_{2}\right) \mathrm{v}_{1}, \mathrm{v}_{2} \in$ $V, x \in R$, Since $\mathrm{e}^{\mathrm{T}}$ is operator then $\mathrm{e}^{\mathrm{T}}$ is linear transformation, this gives $\mathrm{e}^{\mathrm{x}} \cdot \mathrm{e}^{\mathrm{T}}\left(\mathrm{v}_{1}\right)=\mathrm{e}^{\mathrm{x}} \cdot \mathrm{e}^{\mathrm{T}}\left(\mathrm{v}_{2}\right) \rightarrow \mathrm{e}^{\mathrm{T}}\left(\mathrm{e}^{\mathrm{x}} \cdot \mathrm{v}_{1}\right)$ $=\mathrm{e}^{\mathrm{T}}\left(\mathrm{e}^{\mathrm{x}} \cdot \mathrm{v}_{2}\right)$, bu $\mathrm{e}^{\mathrm{T}}$ is one to one,then $\mathrm{e}^{\mathrm{x}} \cdot \mathrm{v}_{1}=\mathrm{e}^{\mathrm{x}} \cdot \mathrm{v}_{2} \rightarrow\left(\mathrm{v}_{1}-\mathrm{v}_{2}\right) \mathrm{e}^{\mathrm{x}}=0$, but $\mathrm{e}^{\mathrm{x}} \neq 0$ then $\quad \mathrm{v}_{1}=\mathrm{v}_{2}$ this gives either $\mathrm{e}^{\mathrm{T}}\left(\mathrm{v}_{1}\right) \neq \mathrm{e}^{\mathrm{T}}\left(\mathrm{v}_{2}\right) \quad$ or $\mathrm{e}^{\mathrm{T}}\left(\mathrm{v}_{1}\right)=\mathrm{e}^{\mathrm{T}}\left(\mathrm{v}_{2}\right)$ but if $\mathrm{e}^{\mathrm{T}}\left(\mathrm{v}_{1}\right) \neq \mathrm{e}^{\mathrm{T}}\left(\mathrm{v}_{2}\right)$ this gives $\mathrm{v}_{1} \neq \mathrm{v}_{2}$ this contradction with assume $\mathrm{v}_{1}=\mathrm{v}_{2}$, then $\mathrm{e}^{\mathrm{T}}\left(\mathrm{v}_{1}\right)=\mathrm{e}^{\mathrm{T}}\left(\mathrm{v}_{2}\right) \quad$ this means $\mathrm{a}=\mathrm{b}$ which is a contradction, then $V_{T}$ is separated S-act.

In the following proposition we give the converse of the proposition (10)

Proposition 11. If $V_{T}$ is separated then $\mathrm{T}$ is one to one.

Proof: Assume $V_{T}$ is separated, we want to prove $T$ is one to one, let $\mathrm{v}_{1} \neq \mathrm{v}_{2}$ we must prove $\mathrm{T}\left(\mathrm{v}_{1}\right) \neq$ $T\left(\mathrm{v}_{2}\right)$,since $\quad \mathrm{v}_{1} \neq \mathrm{v}_{2}$ then either $\mathrm{e}^{\mathrm{T}}\left(\mathrm{v}_{1}\right) \neq \mathrm{e}^{\mathrm{T}}\left(\mathrm{v}_{2}\right)$ or $\mathrm{e}^{\mathrm{T}}\left(\mathrm{v}_{1}\right)=\mathrm{e}^{\mathrm{T}}\left(\mathrm{v}_{2}\right)$ if $\mathrm{e}^{\mathrm{T}}\left(\mathrm{v}_{1}\right)=\mathrm{e}^{\mathrm{T}}\left(\mathrm{v}_{2}\right)$ this contradction with $\mathrm{v}_{1} \neq \mathrm{v}_{2}$, then

$\mathrm{e}^{\mathrm{T}}\left(\mathrm{v}_{1}\right) \neq \mathrm{e}^{\mathrm{T}}\left(\mathrm{v}_{2}\right)$, but $V_{T}$ is separated $\mathrm{S}$ act then $\exists \mathrm{e} \neq \mathrm{s} \in S$ such that $\mathrm{e}^{\mathrm{x}} \cdot \mathrm{e}^{\mathrm{T}}\left(\mathrm{v}_{1}\right) \neq$ $e^{\mathrm{x}} \cdot \mathrm{e}^{\mathrm{T}}\left(\mathrm{v}_{2}\right)$, Since $\mathrm{e}^{\mathrm{T}}$ is operator then $\mathrm{e}^{\mathrm{T}}$ is

linear transformation, this gives $\mathrm{e}^{\mathrm{x}} \cdot \mathrm{e}^{\mathrm{T}}\left(\mathrm{v}_{1}\right)=\mathrm{e}^{\mathrm{x}} \cdot \mathrm{e}^{\mathrm{T}}\left(\mathrm{v}_{2}\right) \rightarrow$ $\mathrm{e}^{\mathrm{T}}\left(\mathrm{e}^{\mathrm{x}} \cdot \mathrm{v}_{1}\right) \neq \mathrm{e}^{\mathrm{T}}\left(\mathrm{e}^{\mathrm{x}} \cdot \mathrm{v}_{2}\right)$, this mean $\left(1+T+\frac{T^{2}}{2 !}+\frac{T^{3}}{3 !}+\cdots\right)\left(\mathrm{e}^{\mathrm{x}} \cdot \mathrm{v}_{1}\right) \neq(1+$ $\left.T+\frac{T^{2}}{2 !}+\frac{T^{3}}{3 !}+\cdots\right)\left(\mathrm{e}^{\mathrm{x}} \cdot \mathrm{v}_{2}\right)$, we get $\mathrm{e}^{\mathrm{x}} \cdot \mathrm{v}_{1}+\mathrm{T}\left(\mathrm{e}^{\mathrm{x}} \cdot \mathrm{v}_{1}\right)+\frac{T^{2}}{2 !}\left(\mathrm{e}^{\mathrm{x}} \cdot \mathrm{v}_{1}\right)+$ $\frac{T^{3}}{3 !}\left(\mathrm{e}^{\mathrm{x}} \cdot \mathrm{v}_{1}\right)+\cdots \neq \mathrm{e}^{\mathrm{x}} \cdot \mathrm{v}_{2}+\mathrm{T}\left(\mathrm{e}^{\mathrm{x}} \cdot \mathrm{v}_{2}\right)+$ $\frac{T^{2}}{2 !}\left(\mathrm{e}^{\mathrm{x}} \cdot \mathrm{v}_{2}\right)+\frac{T^{3}}{3 !}\left(\mathrm{e}^{\mathrm{x}} \cdot \mathrm{v}_{2}\right)+\cdots$ $\mathrm{e}^{\mathrm{x}} \cdot \mathrm{v}_{1} \neq \mathrm{e}^{\mathrm{x}} \cdot \mathrm{v}_{2}, \mathrm{~T}\left(\mathrm{e}^{\mathrm{x}} \cdot \mathrm{v}_{1}\right) \neq \mathrm{T}\left(\mathrm{e}^{\mathrm{x}} \cdot \mathrm{v}_{2}\right)$, but $\mathrm{T}$ is operator, hence $\mathrm{e}^{\mathrm{x}} \cdot \mathrm{T}\left(\mathrm{v}_{1}\right) \neq$ $\mathrm{e}^{\mathrm{x}} \cdot \mathrm{T}\left(\mathrm{v}_{2}\right)$, but $\mathrm{e}^{\mathrm{x}} \neq 0$ then $\mathrm{T}\left(\mathrm{v}_{1}\right) \neq$ $\mathrm{T}\left(\mathrm{v}_{2}\right)$, and $\frac{T^{2}}{2 !}\left(\mathrm{e}^{\mathrm{x}} \cdot \mathrm{v}_{1}\right) \neq \frac{T^{2}}{2 !}\left(\mathrm{e}^{\mathrm{x}} \cdot \mathrm{v}_{2}\right)$ $\frac{T}{2 !}\left(\mathrm{T}\left(\mathrm{e}^{\mathrm{x}} \cdot \mathrm{v}_{1}\right)\right) \neq \frac{T}{2 !}\left(T\left(\mathrm{e}^{\mathrm{x}} \cdot \mathrm{v}_{2}\right)\right)$, so $\mathrm{T}\left(\mathrm{e}^{\mathrm{x}} \cdot \mathrm{v}_{1}\right) \neq \mathrm{T}\left(\mathrm{e}^{\mathrm{x}} \cdot \mathrm{v}_{2}\right)$, by using the same way we get $\mathrm{T}\left(\mathrm{v}_{1}\right) \neq \mathrm{T}\left(\mathrm{v}_{2}\right), \ldots \ldots$, then we prove $\mathrm{T}$ is one to one.

In the following proposition we introduce another conditions to get $\mathrm{V}$ is cyclic which is every cyclic is finite dimensional.

Recall that $M_{S}$ be an S-system and $\mathrm{H}$ a subset of $\mathrm{S}$.then $\mathrm{H}$ is called reductive on $M_{S}$ if and only if for each 
$\mathrm{a}, \mathrm{b} \in M_{s}, a h=b h$ for all $\mathrm{h} \in H$ implies $\mathrm{a}=\mathrm{b}$, an singular relation $\psi_{M}$ on $M_{S}$ by the set

$\{(a, b) \epsilon M \times M \backslash a h=$

bh for some heHfor some reductive subset HofS $\}$ . [8]

Proposition 12. If $V_{T}$ is singular S-act then $\mathrm{V}$ is generated by one element.

Proof: since $V_{T}$ is singular $\mathrm{S}$-act then $\psi_{V=}\left\{\left(\mathrm{e}^{\mathrm{T}}\left(\mathrm{v}_{1}\right), \mathrm{e}^{\mathrm{T}}\left(\mathrm{v}_{2}\right)\right) \epsilon V_{T} \times V_{T} \backslash \mathrm{e}^{\mathrm{x}} \cdot \mathrm{e}^{\mathrm{T}}\left(\mathrm{v}_{1}\right)=\right.$

$\mathrm{e}^{\mathrm{x}} \cdot \mathrm{e}^{\mathrm{T}}\left(\mathrm{v}_{2}\right)$ for some $\mathrm{e}^{\mathrm{x}} \in H$ for some reductive subset Hof $\left.S\right\}$

Then $\mathrm{e}^{\mathrm{x}} \cdot \mathrm{e}^{\mathrm{T}}\left(\mathrm{v}_{1}\right)=\mathrm{e}^{\mathrm{x}} \cdot \mathrm{e}^{\mathrm{T}}\left(\mathrm{v}_{2}\right) \ldots(1)$,

hence $e^{T}\left(e^{x} \cdot v_{1}\right)=e^{T}\left(e^{x} \cdot v_{2}\right)$, since $e^{T}$ is one to one, therefore $e^{\mathrm{x}} \cdot \mathrm{v}_{1}=\mathrm{e}^{\mathrm{x}} \cdot \mathrm{v}_{2}$, then

$\mathrm{e}^{\mathrm{x}} \cdot \mathrm{v}_{1}+(-1) \mathrm{e}^{\mathrm{x}} \cdot \mathrm{v}_{2}=0 \ldots(2)$, but $\mathrm{H}$ is reductive subset of $S$, then by (1). We find $\mathrm{e}^{\mathrm{T}}\left(\mathrm{v}_{1}\right)=\mathrm{e}^{\mathrm{T}}\left(\mathrm{v}_{2}\right)$, but $\mathrm{e}^{\mathrm{T}}$ is one to one, then $v_{1}=v_{2}$, we replies $v_{1}=v_{2}$ on (2), then $\mathrm{e}^{\mathrm{x}} \cdot \mathrm{v}_{1}+(-1) \mathrm{e}^{\mathrm{x}} \cdot \mathrm{v}_{1}=0$, then $\mathrm{V}$ is generated by one element, this give $\mathrm{V}$ is finite dimension.

Recall that an act $A_{S}$ is called torsion free if for any $\mathrm{x}, \mathrm{y} \in A_{S}$, and for any right cancellable element $\mathrm{c} \in S$, the equality $\mathrm{xc}=\mathrm{yc}$ this implies $\mathrm{x}=\mathrm{y}$. [1]

Proposition 13. For any bounded operator $\mathrm{T}$ then $V_{T}$ is torsion free $\mathrm{S}$-act.

Proof: Assume $\quad \mathrm{e}^{\mathrm{x}} \cdot \mathrm{e}^{\mathrm{T}}\left(\mathrm{v}_{1}\right)=$ $\mathrm{e}^{\mathrm{x}} \cdot \mathrm{e}^{\mathrm{T}}\left(\mathrm{v}_{2}\right), \forall \mathrm{e}^{\mathrm{x}}$ is cancellable element in $\mathrm{S}$, this gives $\mathrm{e}^{\mathrm{T}}\left(\mathrm{e}^{\mathrm{x}} \cdot \mathrm{v}_{1}\right)=\mathrm{e}^{\mathrm{T}}\left(\mathrm{e}^{\mathrm{x}} \cdot \mathrm{v}_{2}\right)$, since $\mathrm{e}^{\mathrm{T}}$ is one to one, this gives $\left(\mathrm{e}^{\mathrm{x}} \cdot \mathrm{v}_{1}\right)$ $=\left(e^{\mathrm{x}} \cdot \mathrm{v}_{2}\right)$, thus $\mathrm{v}_{1}=\mathrm{v}_{2}$, then either $\mathrm{e}^{\mathrm{T}}\left(\mathrm{v}_{1}\right)=\mathrm{e}^{\mathrm{T}}\left(\mathrm{v}_{2}\right)$ or $\mathrm{e}^{\mathrm{T}}\left(\mathrm{v}_{1}\right) \neq \mathrm{e}^{\mathrm{T}}\left(\mathrm{v}_{2}\right)$, if $\mathrm{e}^{\mathrm{T}}\left(\mathrm{v}_{1}\right) \neq \mathrm{e}^{\mathrm{T}}\left(\mathrm{v}_{2}\right)$, we get a contradiction with $\mathrm{v}_{1}=\mathrm{v}_{2}$, then $\mathrm{e}^{\mathrm{T}}\left(\mathrm{v}_{1}\right)=$ $\mathrm{e}^{\mathrm{T}}\left(\mathrm{v}_{2}\right)$, thus $V_{T}$ is torsion free.

In the following proposition we introduce sufficient and necessary conditions on $\mathrm{V}$ in order that $V_{T}$ is a Noetherian S-act, we need some definitions to clear this proposition.

Recall that a monid $\mathrm{S}$ is right Noetherian if and only if it satisfies the asending chain condition for right ideals, this mean for every a sending chain $K_{1} \subseteq K_{2} \subseteq K_{3} \subseteq \ldots \subseteq K_{n} \subseteq K_{n+1} \subseteq \ldots$ Of its right ideals, there exists $\mathrm{n} \in \mathrm{N}$ such that $K_{n}=K_{n+1}=\ldots \quad$ [1]
In [9] show that an act $A_{S}$ is called Noetherian if it satisfies the asending chain condition for right sub acts, this mean for every asending chain

$K_{1} \subseteq K_{2} \subseteq K_{3} \subseteq \ldots \subseteq K_{n} \subseteq K_{n+1} \subseteq \ldots$

Of its right sub acts, there exists $\mathrm{n} \in \mathrm{N}$ such that $K_{n}=K_{n+1}=\ldots$

Theorem 14. If $\mathrm{S}$ is Noetherian and $\mathrm{A}$ is finitely generated $\mathrm{S}$-act then $\mathrm{A}$ is Noetherain S-act. [9]

Proposition 15. Let $\mathrm{V}$ is a finite dimensional normed space and $\mathrm{T}$ is similar to any operator $\mathrm{J}$ from $\mathrm{R}$ to $\mathrm{R}$ then $V_{T}$ is Noetherian S-act if and only if $\mathrm{S}$ is Noetherian.

Proof: Since V is finite dimensional then $V_{T}$ is finitely generated $S$-act by remark (8), therefore $V_{T}$ is Noetherian $S$ act, by theorem (14).

Let $\mathrm{K}_{1} \subseteq \mathrm{K}_{2} \subseteq \mathrm{K}_{3} \subseteq \ldots \subseteq \mathrm{K}_{\mathrm{n}} \subseteq$ $\mathrm{K}_{\mathrm{n}+1} \subseteq \ldots$ be any ascending sequence ideals of $S$, then it is a sequence of subacts of $\mathrm{S}_{\mathrm{S}}$ denoted $\mathrm{S}_{\mathrm{J}}$, where $\mathrm{J}$ any operator from $\mathrm{R}$ to $\mathrm{R}$, since $\mathrm{T}$ is similar to $\mathrm{J}$, then by Proposition (6), $\mathrm{V}_{\mathrm{T}}$ is isomorphic to $S_{J}$, thus $S_{J}$ is Noetherian $\mathrm{S}$ - act, therefore this sequence is finite, then $\mathrm{S}$ is Noetherian.

\section{References:}

[1] Kilp, M; Knauer, U and Mikhalev, A. 2000. Monoids, Acts and Categories. Walter de Gruyter, Berlin, New York.

[2] Dahash, A. A. 2014. Injectivity and S-systems. A thesis of Master in science in Mathematics, College of Science Al-Mustansiriya University.

[3] Ahmed, F.A. 2013. Elementary Functions of Bounded Linear Operators. A thesis of Master in Science in Mathematics. College of Science for Women Baghdad University.

[4] Mariano Giaquinta; Giueppe Modica. 2007. Mathematical Structure and continuity. Springer, Italy. PP465. 
[5] Faris, S.M. 1994. Linear Operators and Modules. A thesis of Master in Science in Mathematics. College of Science Baghdad University.

[6] Berberian, S. K. 1961. Introduction to Hilbert space. Chelsea publishing company, New York N.Y.

[7] Moghaddasi, Gh. 2012. Sequentially Injective and Complete Acts over A semigroup. J. Nonlinear Science. Application.

[8] Kim, J. 2008. PI-S-Systems. Journal of the Chung cheong Mathematical Society, volume 21.NO.4.

[9] Ahmadi, K; Madanshekaf, A. 2014. Nakayama ś Lemma on Act. Department of Mathematics, Semnan University, Iran.

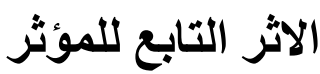

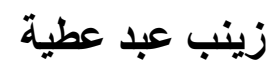

\section{سميرة نـاجي كاظم \\ قسم الرياضيات، كلية العلوم للبنات، جامعة بغداد.}

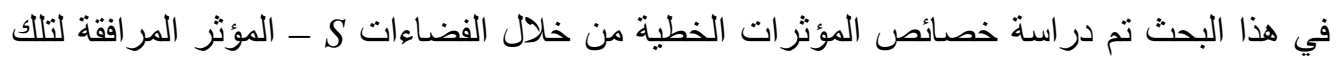

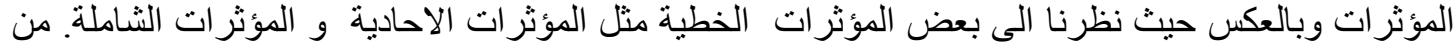

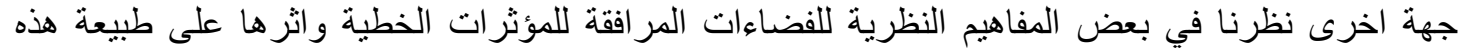

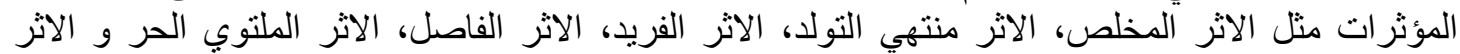

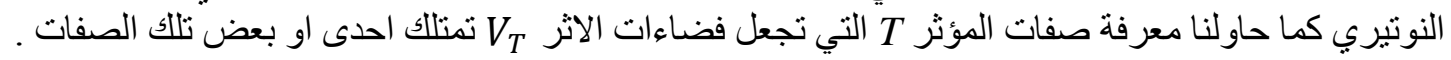

الكلمات المفتاحية: الاثر المخلص، الاثر المنتهي التولد، الاثر الفريد، الاثر الفاصل، الاثر الملتوي الحر و الاثر النوتيري. 